\title{
Experiments in use of bentonite for energy recovery of used oils
}

\author{
Mihai Dragne ${ }^{1}$, Elena Pop ${ }^{* 1}$ Cristina Ileana Covaliu' ${ }^{2}$ Ecaterina Matei ${ }^{3}$, Ionel Pîşăă \\ ${ }^{1}$ University Politehnica of Bucharest Faculty of Mechanical Engineering and Mechatronics, \\ Department of Thermodynamics, Engines, Thermal and Refrigeration Equipment, Romania; \\ ${ }^{2}$ University Politehnica of Bucharest, Faculty of Biotechnical Systems Engineering, Department of \\ Biotechnical Systems, Romania; \\ ${ }^{3}$ University Politehnica of Bucharest, Faculty of Materials Science and Engineering, Department of \\ Biotechnical Systems, Romania;
}

\begin{abstract}
The paper proposes the development of advanced, integrated technologies for materials with properties of adsorbents (e.g. bentonite), and the use of these material in processes of used oil recovery with remediation effect and energy recovery. The main objective is to replace diesel fuel, which is an expensive fuel, with revitalized oils for energy production. For these, laboratory experiments are required in two important directions. The first tests are related to the determination the optimum concentration of bentonite for removal of metals from used oil. The revitalization of the used oil leads to the protection of the combustion plant, to the increase of its lifetime and polluting emissions reduction. The second set of experiments relates to the determination of energy characteristics of used oil and revitalized used oil for energy production. Elemental analysis, lower heating value, viscosity, density and ash analysis were determined. Experimental test of combustion process on a small scale boiler has been done and the results shows an improved combustion process of revitalized oil compares with used oil and the decrease of the pollutant emissions.
\end{abstract}

\section{Introduction}

Environmental pollution is a topical issue and trying to obtain non-polluting fuels or to recover waste materials for energy purpose concerns many researchers today. It is necessary to solve the problem of waste oil from road vehicles according to DIRECTIVE 2008/98/EC on waste and the national legislation in force: Decision no 235 of 7 March 2007. The legislation provides all operations by which waste oils transferred from the holder to the economic operators who can collect, recover or eliminate those oils or use them as fuel with adequate heat recovery. The present research studies the problem of waste oils from the automotive industry and the possibility of their regeneration with energy recovery. Motor oils are used to lubricate the components of the engine assembly and the

\footnotetext{
* Corresponding author: elena.pop@upb.ro
} 
essential properties of it are: Greasing/lubrication to reduce friction between moving parts, cooling of the parts with which it comes into contact, especially the piston, cleaning of the parts on which residues of the combustion process are deposited (e.g. cylinders, segments, piston), protection against chemical corrosion of engine parts. The used motor oils are contaminated by contaminants and impurities resulted from undesirable oxidation processes: sediment, water, metallic particles and degraded additives [1]. There are several methods to remove these contaminants. The technology proposed in the present research is aimed for the process of revitalization of residual oils from motor engines by contacting them semi-dynamic, with natural/modifies nanostructured compounds [2]. In this regard we choose bentonite as nanostructured material. Bentonite powder plays an important role in the regeneration and clarifying of wastes [3]. Research regarding the wastewater treatment using bentonite clay due to chemical composition and crystal morphology, which are indicative of effective physicochemical adsorption [4] shows that the structural configuration (octahedral and tetrahedral) is effective in sorption by intercalation of the turbid materials (heavy metals) onto the sheets and porous surface of the bentonite clay. Bentonite has also been reported to have a high adsorption capacity for heavy metals due to its high specific surface area, small particle size, high porosity and high cation exchange capacity [5] The adsorption technique has been found to be superior to the other techniques for removal of heavy metals, in terms of cost, flexibility, simplicity of design, ease of operation, insensitivity to toxic pollutants and better removal efficiency [6].

\section{Experimental determinations}

\subsection{Materials and methods}

Samples analyzed are two types of used motor oils: one comes from an spark-ignition engine from a Renault vehicle brand, Symbol model, $1589 \mathrm{~cm} 3$ cylinder capacity, manufactured in 2008, and the other from a compression-ignition engine from a Volkswagen vehicle brand, Passat model, $1989 \mathrm{~cm} 3$ cylinder capacity, production year 2008.

As material for regenerating the used oil, activated Bentonite has been used. Activated bentonite is obtained by processing the crude bentonite $\mathrm{Al}_{2} \mathrm{O}_{3} \cdot 4 \mathrm{SiO}_{2} \cdot 4 \mathrm{H}_{2} \mathrm{O}$ exploited from the calcium bentonite quarry from Orasu-Nou, activated by a specific process. Due to the many physical and chemical properties such as high water absorption capacity, high ion exchange capacity, high intercrystalline swelling in aqueous medium and high plasticity, bentonite can be appropriate for contaminants removal. The purpose of using bentonite in this experiment is related to its absorption capacity of the contaminants and regeneration of the waste motor oil Technical characteristics of bentonite are: Maximum granulation: rest on sieve $\varnothing 0,063 \mathrm{~mm}-\max .25 \%$ bulk density: $800-850 \mathrm{~kg} / \mathrm{m} 3$, humidity: $\max .10 \% \mathrm{pH}$ : min. 8 , bentonite number: $\min .0,85$.

\subsection{Physical and chemical characterization of used oil}

The physico-chemical characteristics of motor oils change as a result of their exploitation [3]. The operating conditions lead to pollutants accumulation in the oil that change the quality of engine oil. Analyzes on density and viscosity of the different kind of motor oils (raw and used) were performed. Three samples have been considered: raw motor oil, waste oil from spark-ignition engine and waste oil from a compression-ignition engine

The carbon $(\mathrm{C})$, nitrogen $(\mathrm{N})$, hydrogen $(\mathrm{H})$ and sulphur $(\mathrm{S})$ contents of the waste motor oil samples were determined by a CHNS elemental analyzer EA 1110. Determinations were performed at ICEMENERG. The Lower Heating Power was determined according to ASTM D240-17; 


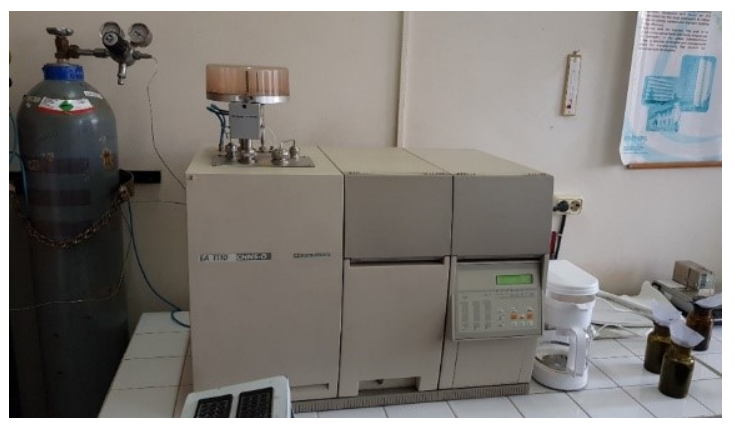

Fig.1 Elemental analyzer EA 1110

\subsection{Regeneration of used oil using bentonite}

The regeneration was done on used crude MAC oil. Different amounts of bentonite $(20 \mathrm{~g}$, $40 \mathrm{~g}, 60 \mathrm{~g}, 80 \mathrm{~g}, 90 \mathrm{~g}$ ) were added in a volume of $400 \mathrm{~mL}$ of used oil. Each sample was homogenized for 2 weeks, 8 hours per day at room temperature and $300 \mathrm{rpm}$. Samples were taken from each set of experiments having different amounts of bentonite in order to quantify the amount of metal adsorbed by bentonite. The analysis of heavy metals was carried out by heat treatment of the samples at $800^{\circ} \mathrm{C}$ and the resulting ash was taken up for atomic absorption analysis.

\subsection{Tests for combustion processes}

The experimental researches were conducted in the Combustion laboratory of the Department of Thermodynamics, Engines, Thermal and Refrigeration Equipment, Faculty of Mechanical Engineering and Mechatronics of Politehnica University of Bucharest.

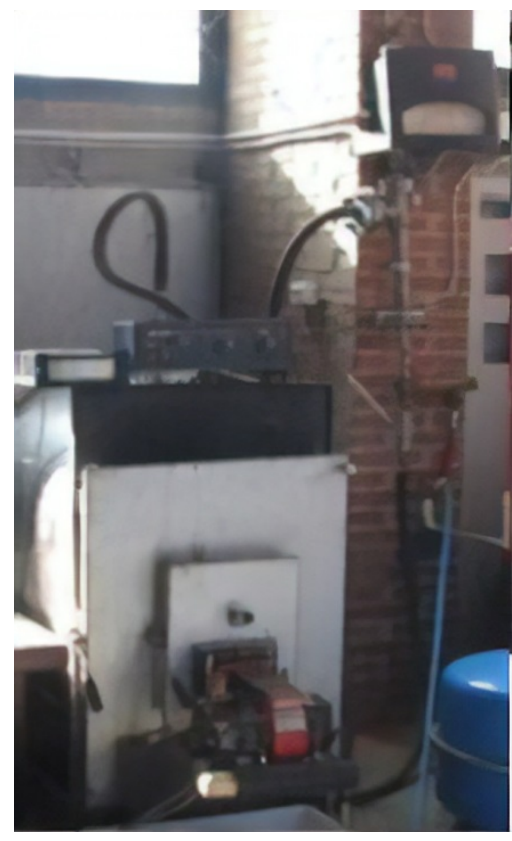

Fig 2 Experimental pilot boiler of $55 \mathrm{~kW}$

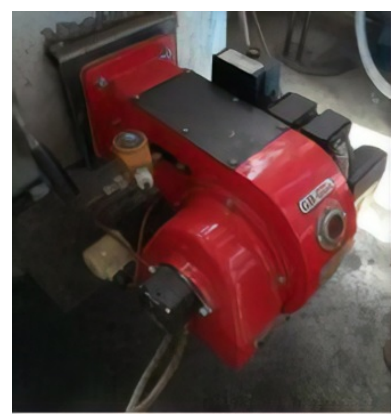

Fig. 3 burnerAnyo-12

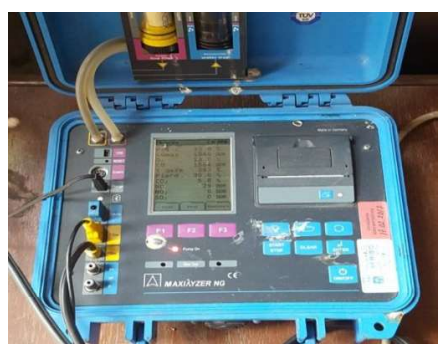

Fig. 4 Flue gas analyzer 


\section{MAXILYZER NG}

For combustion tests a pilot boiler of $55 \mathrm{~kW}$ has been used. The boiler is equipped with a special burner for liquid which ensures the preheating of the fuel up to $80^{\circ} \mathrm{C}$, temperature imposed by the high viscosity of the analyzed fuel.

For the tests, used diesel oil and regenerated used diesel oil after treatment with bentonite (P1 with 20g bentonite) has been used. For comparison of combustion process, we also used diesel fuel. During the experiments the pollutant emissions from the flue gases has been analyzed using a Maxilyser NG gas analyzer.

\section{Results and discussion}

High viscosity of used motor oil determined during the experiments (see table 1) imposes the necessity of used oil preheating for the combustion process.

Table 1. Viscosity and density of motor oil

\begin{tabular}{|l|l|c|c|c|}
\hline & Type of sample /property & Temperature, $\mathbf{t}$ & Viscosity & Density, $\boldsymbol{\rho}$ \\
\cline { 3 - 5 } & & ${ }^{\circ} \mathrm{C}$ & $E^{0}$ & $\mathrm{Kg} / \mathrm{m}^{3}$ \\
\hline 1. & Raw motor oil & 75 & 2,4 & $840-850$ \\
\hline 2. & Used oil from spark-ignition engine & 75 & 2,6 & $870-880$ \\
\hline 3. & Used oil from compression-ignition engine & 75 & 2,7 & $840-850$ \\
\hline
\end{tabular}

The results of the elemental analysis are presented in the table below:

Table 2 Elemental analysis of the used oil

\begin{tabular}{|l|c|c|c|c|c|}
\hline \multirow{2}{*}{ Type of sample } & $\boldsymbol{C}$ & $\boldsymbol{H}$ & $\boldsymbol{N}$ & $\boldsymbol{S}$ & $\boldsymbol{L H} \boldsymbol{V}$ \\
\cline { 2 - 6 } & $\%$ & $\%$ & $\%$ & $\%$ & $\mathrm{MJ} / \mathrm{kg}$ \\
\hline $\begin{array}{l}\text { Used oil from spark-ignition } \\
\text { engine }\end{array}$ & 83,56 & 13,77 & 0,41 & 0 & 41,96 \\
\hline $\begin{array}{l}\text { Used oil from compression- } \\
\text { ignition engine }\end{array}$ & 84,12 & 14,29 & 0,33 & 0 & 42,33 \\
\hline
\end{tabular}

The composition of the used motor oil and the value of LHV is comparable with liquid fossil fuel as diesel fuel and this recommends it for energy recovery.

The analysis of ash content resulted after thermal treatment of used motor oil with different amount of bentonite in order to quantify the amount of metal adsorbed are presented below.

Table 3 Ash content analysis results - by atomic absorption analysis (AAS)

\begin{tabular}{|l|c|c|c|c|c|}
\hline Amount of sample [g] & $\begin{array}{c}\mathbf{P 5} \\
\mathbf{9 0} \mathbf{g}\end{array}$ & $\begin{array}{c}\mathbf{P 4} \\
\mathbf{8 0 g}\end{array}$ & $\begin{array}{c}\mathbf{P 3} \\
\mathbf{6 0 g}\end{array}$ & $\begin{array}{c}\mathbf{P 2} \\
\mathbf{4 0 g}\end{array}$ & $\begin{array}{c}\mathbf{P 1} \\
\mathbf{2 0 g}\end{array}$ \\
\hline $\boldsymbol{C} \boldsymbol{u}$ & & & & & \\
\hline $\boldsymbol{Z} \boldsymbol{F e t a l s ~ c o n t e n t ~}[\mathbf{m g} / \mathbf{g}]$ & 1.367 & 1.275 & 0.86 & 0.432 & 0.203 \\
\hline $\boldsymbol{F}$ & 98.76 & 74.58 & 72.26 & 46.38 & 45.88 \\
\hline $\boldsymbol{C} \boldsymbol{P} \boldsymbol{P}$ & 7.198 & 3.563 & 3.156 & 3.01 & 2.233 \\
\hline $\boldsymbol{C} \boldsymbol{l}$ & 0 & 0 & 0 & 0 & 0 \\
\hline
\end{tabular}

From the analysis of the results, we find that the sample P1 had the lowest content of metals so we chose this sample for the combustion experiments. Also regarding the possibility of removal of heavy metal content by adsorption on bentonite material, using the lowest amount of bentonite conducted to the highest adsorption of heavy metals from used oil. 
The combustion process of the sample $\mathrm{P} 1$ was analyzed in terms of pollutants emissions and efficiency of the process and the results are presented below:

Table 4 Result of the combustion experimental tests

\begin{tabular}{|l|c|c|c|c|c|}
\hline \multirow{2}{*}{ Type of fuel tested } & $\mathbf{O}_{\mathbf{2}}{ }^{*}$ & $\mathbf{C O}$ & $\mathbf{C O}_{\mathbf{2}}$ & $\mathbf{N O}_{\mathbf{X}}$ & $\mathbf{T}_{\text {evac }}$ \\
\cline { 2 - 6 } & $\mathbf{\%}$ & $\mathbf{p p m}$ & $\mathbf{\%}$ & $\mathbf{p p m}$ & ${ }^{\circ} \mathbf{C}$ \\
\hline Diesel Fuel & 6 & $2869-3034$ & 8,7 & $24-29$ & 192 \\
\hline Raw Waste diesel oil & 6 & $5032-5073$ & 10 & $59-64$ & 224 \\
\hline $\begin{array}{l}\text { Regenerated waste diesel oil with } \\
\text { bentonite }\end{array}$ & 6 & $4146-4158$ & 10 & $54-58$ & 231 \\
\hline
\end{tabular}

*All samples were corrected for standard oxygen concentration of $6 \%$

The concentration of $\mathrm{CO}$ in flue gas is high because we used a burner design for CLU combustion coupled with a natural circulation boiler, strongly cooled and the burner's thermal power is lower than the furnace thermal power. It is mentioned that $\mathrm{CO}$ emitted in the flame does not burn below the temperature of $750 \mathrm{C}$, the temperature reached only in the final part of the furnace. Considering all this, it is recommended a boiler with chamotte insulation, uncooled which due to high combustion temperature will significantly reduce the final $\mathrm{CO}$ emissions. Analyzing the results of the combustion process, we note that the used oil regenerated with bentonite has better performance compared to raw used oil with a decrease of CO emissions of about $18 \%$.

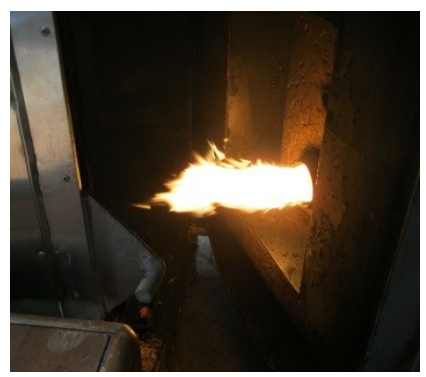

$\mathrm{a}$

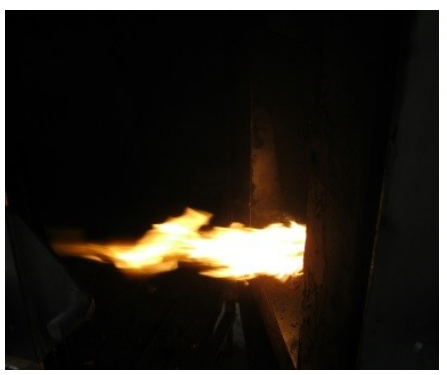

b

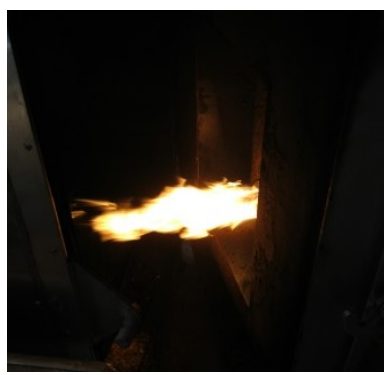

c

Fig. 5. Aspect of flame in the burning process a. diesel oil; b. raw used oil; c. regenerated used oil

Due to the low volatile matter content of the used oil motor the flame presents pulses and a longer length than the reference flame (diesel oil). It is noted that the regenerated oil has attenuated pulses comparing with raw used oil and the ignitions closer to the spray nozzle. The use of bentonite as a material to regenerate used engine oils proves to be an effective solution in lowering the metal content and improving the combustion process.

The reducing of metals concentration in used oil influence directly the burner lifetime by protecting the spray nozzle.

Improvement of the combustion process was achieved by higher flame stability and lower $\mathrm{CO}$ emissions. We expect that by better adaptation of the burner-furnace assembly to increase the efficiency of the combustion process

The results can be extrapolated to other types of used oils such as oils from the energy industry or waste oils from the food industry 


\section{References}

1. Cornelia Stan, Cristian Andreescu, Marius Toma, Some aspects of the regeneration of used motor oil, Procedia Manufacturing, Vol. 22, 2018, Pages 709-713

2. F. Dalla Giovanna, O. Khlebinskaia, A. Lodolo, S. Miertus, Compendium of Used Oil Regeneration Technologies, U.N.I.D.O., Trieste, (2003)

3. Shiva Salem, Amin Salem, Aylin Agha Babaei, Preparation and characterization of nano porous bentonite for regeneration of semi-treated waste engine oil: Applied aspects for enhanced recovery, Chemical Engineering Journal, Vol. 260, 15 January 2015, Pages 368-376

4. Oupa I. Ntwampe and Kapil Moothi, Removal of Heavy Metals Using Bentonite Clay and Inorganic Coagulants, Heavy Metals, Chapter 3, Published: June 27th2018, page 33-51, http://dx.doi.org/10.5772/intechopen.76380

5. Kovo G.Akpomie, Folasegun A.Dawodu Potential of a low-cost bentonite for heavy metal abstraction from binary component system, Beni-Suef University Journal of Basic and Applied Sciences, Volume 4, Issue 1, March 2015, Pages 1-13

6. M.W. Amer, F.L. Khalili, A.M. Awwad Adsorption of lead, zinc and cadmium ions on polyphosphate modified kaolinite clay, J Environ Chem Ecotoxicol, 2 (1) (2010), pp. 01-08

7. Shabanzade, A. Salem, Sh. Salem, Management of adsorbent content in waste motor oil regeneration by spectrophotometricalstudy and effective acidification in production of nano-porous clay, Spectrochimica Acta Part A: Spectrochimica Acta Part A: Molecular and Biomolecular Spectroscopy, 202 (2018) 214-222

8. Tao Wua, Zhifen Wangb, Yanhua Tonga, Yongya Wanga, Luc R. Van Loonc, Investigation of Re(VII) diffusion in bentonite by through-diffusion and modeling techniques, Applied Clay Science 166 (2018) 223-229

9. Oprea I., Pîşă I., Mihăescu L., Prisecaru T., Lăzăroiu Gh., Negreanu G., Research on the Combustion of Crude Vegetable Oils for Energetic Purposes, Environmental Engineering and Management Journal, Vol.8, No.3, (May/June 2009), pg.475-482, indexat de ISI, Thomson Scientific Proceedings;

10. F. Danane, A. Ahmia, A. Bakiri, N. Lalaoui, Experimental regeneration process of used oil Revue des energies Renouvelables Vol. $17 N^{0} 2$ (2014) 345-351

11. Temitayo E., Oladimeji, Jacob A. Sonibare, James A. Omoleye, Abiola A. Adegbola, Hilary I. Okagbue Data on the treatment of used lubricating oil from two different sources using solvent extraction and adsorption, Data in Brief 19 (2018) 2240-2252

12. Doaa I. Osman, Sayed K. Attia, Afaf R. Taman Recycling of used engine oil by different solvent, Egyptian Journal of Petroleum 27 (2018) 221-225 